\title{
Biomass management targets and the conservation and economic benefits of marine reserves
}

\author{
Satoshi Yamazaki ${ }^{1}$, Quentin R Grafton ${ }^{2,3}$, Tom Kompas ${ }^{3}$ E Sarah Jennings ${ }^{1}$ \\ ${ }^{1}$ School of Economics and Finance, University of Tasmania, TAS, 7001, Australia; ${ }^{2}$ Bureau of Resources and Energy \\ Economics, ACT, 2601, Australia; ${ }^{3}$ Crawford School of Public Policy, Australian National University, Canberra, ACT, \\ 0200, Australia
}

\begin{abstract}
The establishment of no-take marine reserves has been increasingly promoted as a key measure to achieve conservation and sustainability goals in fisheries. Regardless of the wide range of benefits cited, the effectiveness of reserve establishment depends critically on fisheries management outside the reserves. We construct a bioeconomic model of a fishery that allows for the establishment of a no-take marine reserve and evaluate how the choice of the off-reserve management target influences the effectiveness of reserve establishment. We evaluate two biomass targets: (i) $\mathrm{B}_{\mathrm{MSY}}$ or the biomass that produces the maximum sustainable yield (MSY) and (ii) $\mathrm{B}_{\mathrm{MEY}}$ or the biomass that maximizes the net present value of the returns to fishing. The parameterized model shows that, for a wide range of scenarios, the fishery will be better off in terms of both conservation and economic objectives when the no-take reserve is established in conjunction with the $\mathrm{B}_{\mathrm{MEY}}$ target rather than with the $\mathrm{B}_{\mathrm{MSY}}$ target. Model results further show that the opportunity cost of securing additional fish biomass, in both deterministic and stochastic environments, is lower when the reserve size is increased under the $\mathrm{B}_{\mathrm{MEY}}$ target. This finding is important because marine reserves have been established as a key measure to restore depleted fish stocks, and the results suggest that this objective can be achieved with lower economic costs in a $\mathrm{B}_{\mathrm{MEY}}$ managed fishery.
\end{abstract}

Keywords Fisheries management, fisheries target, marine reserve design, maximum economic yield, maximum sustainable yield

Correspondence: Quentin R Grafton Crawford School of Public Policy, Crawford Building (132), Lennox Crossing, The Australian National University, Canberra, ACT, 0200, Australia Tel.: +61 26125 6558

Fax: +6126125

5448

E-mail: quentin. grafton@anu.edu.au

Received 27 Nov 2011

Accepted 6 Aug

2012

A bioeconomic model incorporating a no-take reserve and alternative biomass 
Economic returns and total biomass in a stochastic environment

Opportunity cost of increasing biomass in a stochastic environment

Environmental uncertainty and optimal reserve size

Effects of reserve size and environmental uncertainty

Optimal reserve size

Conclusions

Acknowledgements

References

\section{Introduction}

Many fisheries around the world face major challenges in restoring depleted fish stocks despite the implementation of stock recovery plans (Caddy and Agnew 2004; Beddington et al. 2007; Worm et al. 2009). Spatial management, including the enforcement of no-take marine reserves, is a key component of stock recovery plans and is used to achieve fisheries conservation goals (Roberts et al. 2005).

Notwithstanding their value in stock recovery, the conservation benefits claimed or shown for no-take reserves also include increases in the size, biomass and diversity of exploited species (Halpern 2003; Lester et al. 2009). No-take reserves can also allow for the spillover of adult fish and larvae from reserves to adjacent fishery areas (e.g. Roberts et al. 2001; Stobart et al. 2009; Goñi et al. 2010; Pelc et al. 2010; Vandeperre et al. 2011) and may also increase the economic return from the fishery (e.g. Grafton et al. 2009; McClanahan 2010).

Despite the wide range of benefits cited for notake reserves, their establishment does not resolve all problems in fisheries (Allison et al. 1998). Moreover, their benefits strictly depend on fisheries management outside the reserves (Sanchirico and Wilen 2002; Smith and Wilen 2003; Sumaila and Armstrong 2006; Ruijs and Janmaat 2007; Little et al. 2011). If no-take reserves are implemented while remaining fishing grounds are subject to open access exploitation, the conservation benefits of no-take reserves are limited unless the reserve size is moderately large (Hannesson 1998). In particular, implementing no-take reserves in an open access fishery decreases the aggregate harvest unless the population is initially overexploited (Pezzey et al. 2000), or significant heterogeneity exists between the reserved and fished areas (Sanchirico and Wilen 2001).

In this paper, we model and quantify the effects of establishing a no-take reserve in terms of the conservation and economic benefits of a fishery under alternative management targets in the harvested fishery. Previous studies found that, even when the fishery is managed to maximize economic returns, the implementation of no-take reserves can in some cases enhance conservation and economic benefits in the fishery (Grafton et al. 2006; Sanchirico et al. 2006; Costello and Polasky 2008). To date, however, there has been no study examining how, and to what extent, the effects of no-take reserves and their optimal size change when the reserves are established in conjunction with alternative management targets.

We assess the effects of implementing no-take reserves of different sizes in conjunction with two widely adopted biomass targets. The first biomass target considered is the $\mathrm{B}_{\mathrm{MSY}}$ target - that is the biomass level that generates the maximum sustainable yield (MSY). Despite a number of criticisms (e.g. Larkin 1977; Punt and Smith 2001), $\mathrm{B}_{\mathrm{MSY}}$ has traditionally been adopted as the default target or used as the basis to develop management reference points in many fisheries (Mace 2001; Hilborn 2007; Froese et al. 2011). The second biomass target considered in this paper is the $\mathrm{B}_{\mathrm{MEY}}$ target - that is the biomass level that maximizes the net present value, or economic yield, of fishing. Increased attention on $\mathrm{B}_{\mathrm{MEY}}$ as an alternative management target (Dichmont et al. 2010; Kompas et al. 2010) has sparked debate about the relative effects of the two targets on the biomass and economic returns of the fishery (Gordon 1954; Smith 1969; Clark 1973; Grafton et al. 2007, 2012; Christensen 2010; Clark et al. 2010). 
Our purpose is to (i) evaluate the effects of the choice of the biomass target outside a no-take reserve on the effectiveness of reserve establishment in deterministic and stochastic environments; and (ii) examine the effect of reserve establishment on the relative merits of the $\mathrm{B}_{\mathrm{MSY}}$ and $\mathrm{B}_{\mathrm{MEY}}$ biomass targets outside a reserve under a range of different fishery environments. In the following section, we construct a bioeconomic model of a fishery that allows for the establishment of a no-take marine reserve and identifies the management target in the harvested fishery as either $\mathrm{B}_{\mathrm{MSY}}$ or $\mathrm{B}_{\mathrm{MEY}}$. Given that the effects of reserve establishment have been shown to be sensitive to different types of uncertainty (Lauck et al. 1998; Mangel 2000; Grafton et al. 2005; Halpern et al. 2006), the bioeconomic model incorporates two forms of environmental uncertainty. The model is parameterized for the Australian red throat emperor (Lethrinus miniatus) fishery, and simulation results are reported. The final section provides concluding comments.

\section{A bioeconomic model incorporating a no-take reserve and alternative biomass targets}

\section{Biomass dynamics}

We constructed a bioeconomic model that integrates a discrete population model of biomass dynamics and an economic model of a fishery. The total population $\left(x_{t}\right)$ consists of two subpopulations such that $x_{t}=x_{t}^{H}+x_{t}^{R}$ where $x_{t}^{H}$ is the harvest population, $x_{t}^{R}$ is the reserve population and the subscription $t=0,1,2, \ldots$ denotes the discrete time index.

The biomass dynamics of each population are specified as:

$$
\begin{aligned}
& x_{t+1}^{H}=x_{t}^{H}+G^{H}\left(x_{t}^{H}, s\right)+T\left(x_{t}^{H}, x_{t}^{R}, s\right)-h_{t} \\
& x_{t+1}^{R}=x_{t}^{R}+G^{R}\left(x_{t}^{R}, s\right)-T\left(x_{t}^{H}, x_{t}^{R}, s\right)
\end{aligned}
$$

where $h_{t}$ is the harvest at time $t$. Harvest of the reserve population is prohibited. Each population has its own population-specific growth function $G^{H}(\cdot)$ and $G^{R}(\cdot)$, and the two sub-populations are related by the transfer function $T(\cdot)$. We assume that the transfer of fish is symmetric, that is, $T(\cdot)$ in Equation (1) at time $t$ is equal to $-T(\cdot)$ in Equation (2) at time $t$. The size of the no-take reserve is defined as the proportion of the carrying capacity $(K)$ that is not exposed to fishing and is determined by the parameter $s \in[0,1]$ (Hannesson 1998; Conrad 1999). The proportion of the exploitable biomass is used as a proxy for geographical closure of fishing grounds, and we assume that the reserve and harvest populations respond as they would to a spatial fishing closure.

The growth functions for the harvest and reserve populations are specified as:

$$
\begin{aligned}
& G^{H}\left(x_{t}^{H}, s\right)=r x_{t}^{H}\left(1-\frac{x_{t}^{H}}{(1-s) K}\right) \text { and } \\
& \mathrm{G}^{R}\left(x_{t}^{R}, s\right)=r x_{t}^{R}\left(1-\frac{x_{t}^{R}}{s K}\right)
\end{aligned}
$$

where $r$ is the intrinsic growth rate.

The specification of the transfer function is based on previous bioeconomic modelling (e.g. Hannesson 1998; Conrad 1999; Sanchirico and Wilen 2001; Grafton et al. 2006) and empirical evidence that fish migration is likely to be density dependent and depend on the reserve size (Kramer and Chapman 1999; Abesamis and Russ 2005; Goñi et al. 2010):

$$
T\left(x_{t}^{H}, x_{t}^{R}, s\right)=m(1-s) K\left(\frac{x_{t}^{R}}{s K}-\frac{x_{t}^{H}}{(1-s) K}\right)
$$

where $m$ is the transfer coefficient that determines the strength of connectivity between the reserve and harvest populations. The multiplicative term $m(1-s) K$ ensures that the spillover between the reserve and harvest populations becomes lower with increased reserve size for a given size of $x_{t}^{H}$ and $x_{t}^{R}$.

\section{Identifying the biomass target $-\mathrm{B}_{\mathrm{MSY}}$ and $\mathrm{B}_{\mathrm{MEY}}$}

To simulate the biomass dynamics of the harvest and reserve populations, we need to specify how the level of harvest in the fishery is determined in each time period when either a $\mathrm{B}_{\mathrm{MSY}}$ or $\mathrm{B}_{\mathrm{MEY}}$ target is adopted in the fishery. To identify the $\mathrm{B}_{\mathrm{MSY}}$ target, we maximize the harvest function at the steady-state equilibrium where the harvest, and levels of the harvest and reserve populations, remains constant over time, that is, $h_{t+1}=h_{t} \equiv \bar{h}$, $x_{t+1}^{H}=x_{t}^{H} \equiv \bar{x}^{H} \quad$ and $\quad x_{t+1}^{R}=x_{t}^{R} \equiv \bar{x}^{R} . \quad$ From Equations (1) to (4), the harvest population at the steady-state equilibrium can be written in terms of the reserve population at the equilibrium as: 


$$
\bar{x}^{H}=\bar{x}^{R}\left[\frac{(1-s) K}{s K}\right]-\frac{r}{m}\left(1-\frac{\bar{x}^{R}}{s K}\right) .
$$

Using this relationship between the harvest and reserve populations at the steady-state equilibrium, we derive in Equation (6) the harvest function in terms of the reserve population:

$$
\begin{aligned}
\bar{h}= & r\left(\bar{x}^{R}\left[\frac{(1-s) K}{s K}\right]-\frac{r}{m}\left(1-\frac{\bar{x}^{R}}{s K}\right)\right) \\
& \left(1-\frac{\bar{x}^{R}\left[\frac{(1-s) K}{s K}\right]-\frac{r}{m}\left(1-\frac{\bar{x}^{R}}{s K}\right)}{(1-s) K}\right) \\
& +r \bar{x}^{R}\left(1-\frac{\bar{x}^{R}}{s K}\right)
\end{aligned}
$$

Given the values of the biological and economic parameters, the $\mathrm{B}_{\mathrm{MSY}}$ target level can be identified by maximizing this harvest function.

By contrast, the $\mathrm{B}_{\mathrm{MEY}}$ target is identified by maximizing the NPV of fishing, that is:

$$
\max _{\left\{h_{t}\right\}_{t=0}^{\infty}} \sum_{t=0}^{\infty}\left(\frac{1}{1+\rho}\right)^{t} \pi\left(h_{t}, x_{t}^{H}, s\right)
$$

subject to Equations (1) to (4), $x_{t}^{i} \geq 0$ and given $x_{0}^{i}, i=H, R$ where $\pi(\cdot)$ is the net profit function and the parameter $\rho \in[0,1]$ is the discount rate. The static $\mathrm{B}_{\mathrm{MEY}}$ target, which maximizes fishing profit at a point in time, is a special case of Equation (7) where the discount rate is assumed to be zero (Gordon 1954).

We specify the net profit function as:

$$
\pi\left(h_{t}, x_{t}^{H}, s\right)=p h_{t}-C\left(h, x_{t}^{H}, s\right)
$$

where $p$ is the unit price of landed fish and $C(\cdot)$ is the harvesting cost function, which is specified as $c\left[(1-s) K / x^{H}\right]^{b} h$ where $c$ and $b$ are parameters. This specification of the harvesting cost function assumes that the fishing cost is subject to a stock effect in which fishing costs are sensitive to the density of the harvest population (Grafton et al. 2007). The strength of the stock effect is determined by the parameter $b \in[0,1]$. A commonly used functional form of the harvesting cost is retained when $b=1$ (Clark 1990).

By solving the maximization problem in Equation (7), we obtain the following system of nonlin- ear equations, which the $\mathrm{B}_{\mathrm{MEY}}$ target must satisfy at the steady-state equilibrium:

$$
\begin{gathered}
\bar{h}=G^{H}\left(\bar{x}^{H}\right)+G^{R}\left(\bar{x}^{R}\right) \\
\rho=G_{\bar{x}^{H}}^{H}+\frac{\pi_{\bar{x}^{H}}}{\pi_{\bar{h}}}+\frac{\left(\rho-G_{\bar{x}^{R}}^{R}\right) T_{\bar{x}^{H}}}{\rho-G_{\bar{x}^{R}}^{R}+T_{\bar{x}^{R}}}
\end{gathered}
$$

Equation (9) is the sustainability condition at the steady-state equilibrium and states that the total harvest is the sum of the additional production of the harvest and reserve populations. Equation (10) represents a modified version of the fundamental equation of renewable resources (Clark and Munro 1975) where a subscript denotes a partial derivative. The fundamental equation implies that, at the steady-state equilibrium, the marginal benefit and marginal cost of delaying the harvest to the next period have to be the same and that the decision whether to delay the harvest for the future depends not only on how the delay of the harvest affects the biological and economic production, but also how it affects the spatial distribution of harvest population over time. The original version of the Clark and Munro fundamental equation can be recovered when there is no fish dispersal such that $T_{\bar{x}^{H}}=0$.

Given that the profit function in Equation (8) is linear in the control variable $h_{t}$, the optimal harvest strategy along a transition path, which maximizes the net economic return from fishing, is the most rapid approach path (MRAP) strategy (Clark 1990). The MRAP strategy ensures the shortest time spent to reach a desirable biomass target $\left(x_{\text {target }}^{H}\right)$ by setting the level of harvest at:

$$
h_{t}=\left\{\begin{array}{ccc}
0 & \text { if } & x_{t}^{H}<x_{\text {target }}^{H} \\
h_{\text {target }} & \text { if } & x_{t}^{H}=x_{\text {target }}^{H} \\
h_{\max } & \text { if } & x_{t}^{H}>x_{\text {target }}^{H}
\end{array}\right.
$$

When the current level of exploitable biomass is less than the target level, the fishery is closed and the harvest set at zero each year. The fishery is only re-opened when the biomass rebuilds above the target. By contrast, when the current level of exploitable biomass is above the target level, the harvest is set at the maximum attainable level $h_{\text {max }}$ until the exploitable biomass falls to the target level. When the exploitable biomass is at the target level, the harvest is set at the level corresponding to the biomass target $\left(h_{\text {target }}\right)$. 


\section{Environmental uncertainty}

The biological and economic effects of no-take reserve establishment are sensitive to different types and levels of uncertainty (Lauck et al. 1998; Mangel 2000; Grafton et al. 2005; Halpern et al. 2006). We thus incorporate two forms of environmental uncertainty in the model as a way of exploring how uncertainty may affect the establishment of no-take reserves when they are implemented in conjunction with different biomass targets.

The first form of uncertainty is temporal variation in population growth that, in our model, is common to both the harvest and reserve populations. Temporal variation is incorporated into the model by modifying the growth functions, as specified in Equation (12);

$$
\begin{aligned}
G^{H}\left(x_{t}^{H}, s, z_{t}^{G}\right) & =r x_{t}^{H} z_{t}^{G}\left(1-\frac{x_{t}^{H}}{(1-s) K}\right) \text { and } \\
G^{R}\left(x_{t}^{R}, s, z_{t}^{G}\right) & =r x_{t}^{R} z_{t}^{G}\left(1-\frac{x_{t}^{R}}{s K}\right)
\end{aligned}
$$

where the random variable $z_{t}^{G}$ has a discrete uniform distribution with mean 1 , that is, $z_{t}^{g} \in\left\{\underline{z}^{g}, \ldots, \bar{z}^{g}\right\}$ and $\left(\underline{z}^{g}+\bar{z}^{g}\right) / 2=1$. Given that the mean of the random variable is one, the random variation in the population growth is, on average, negligible.

The second form of environmental uncertainty incorporated in the model allows for a large negative shock on the harvest population. Following previous studies (Lauck et al. 1998; Sumaila 1998; Jennings 2001; Grafton et al. 2006), we assume that the harvest population is exposed to a risk of random negative effects because of fishing activity. By assumption, harvesting of the reserve population is prohibited and, as a result, fishinginduced negative shocks do not occur on the reserve population, but our results do not qualitatively change should the negative shock be identical in both populations. The negative shock is introduced by modifying the biomass dynamics equation for the harvest population as specified in Equation (13):

$$
\begin{aligned}
x_{t+1}^{H}= & x_{t}^{H}+G^{H}\left(x_{t}^{H}, s, z_{t}^{G}\right)+T\left(x_{t}^{H}, x_{t}^{R}, s\right) \\
& -\eta z_{t}^{s} x_{t}^{H}-h_{t}
\end{aligned}
$$

where the random variable $z_{t}^{s}$ takes a value of either 0 or 1 , that is, $z_{t}^{s} \in\{0,1\}, p\left(z_{t}^{s}=1\right)=\alpha$ and $\alpha \in[0,1]$ is the probability of realizing a negative shock and is referred to as the arrival rate. The parameter $\eta \in[0,1]$ controls the size of negative shocks.

\section{Effects of no-take reserves under alternative biomass targets}

\section{Model parameterization}

Our model results are generated using parameter values from the red throat emperor (Lethrinus miniatus) fishery located on the Great Barrier Reef, Queensland, Australia. We note that the red throat emperor fishery is managed as a single stock so that the fishery is suitable for our singlespecies framework. Leigh et al. (2006) estimate that the intrinsic growth rate is $r=0.12$, and the carrying capacity in the Mackay area of Queensland is $K=6913$ tonnes. Little et al. (2008, 2009) estimate that the average monthly price of landed red throat emperor is $\$ 14.57 / \mathrm{kg}$. Unfortunately, the data do not exist to estimate the parameters for the harvesting cost and transfer functions, and so these parameters are set arbitrarily at $c=4.5$, $b=1$ and $m=0.1$, but the sensitivity of the results to variation in these values is explored as part of the analysis. Temporal variation associated with fish growth is captured by the parameters $\underline{z}^{g}$ and $\bar{z}^{g}$ which are set at 0.9 and 1.1. Uncertainty associated with a negative shock on the harvest population is accounted for by the parameters $\eta=0.4$ and $\alpha=0.04$.

\section{Economic returns and total biomass in a deterministic environment}

Figure 1 illustrates the relative change in the net profit of fishing (Fig. 1a) and the total biomass (Fig. 1b) for five different sizes of no-take reserves at $10 \%, 20 \%, 30 \%, 40 \%$ and $50 \%$ of the carrying capacity, for both the $\mathrm{B}_{\mathrm{MSY}}$ and $\mathrm{B}_{\mathrm{MEY}}$ targets. We note that, following Hannesson (1998) and Conrad (1999), the size of the no-take reserve is defined in terms of the fish population rather than as a proportion of the spatial area of the habitat. Initially, and for comparative purposes only, we assume no environmental uncertainties so that $z_{t}^{G}=1$ and $z_{t}^{s}=0$ for all $t$ and that the net profit of the fishery and total biomass are evaluated at the steady state. The outcome for each reserve size is standardized where the baseline is the no-reserve case $(s=0)$, that is, 

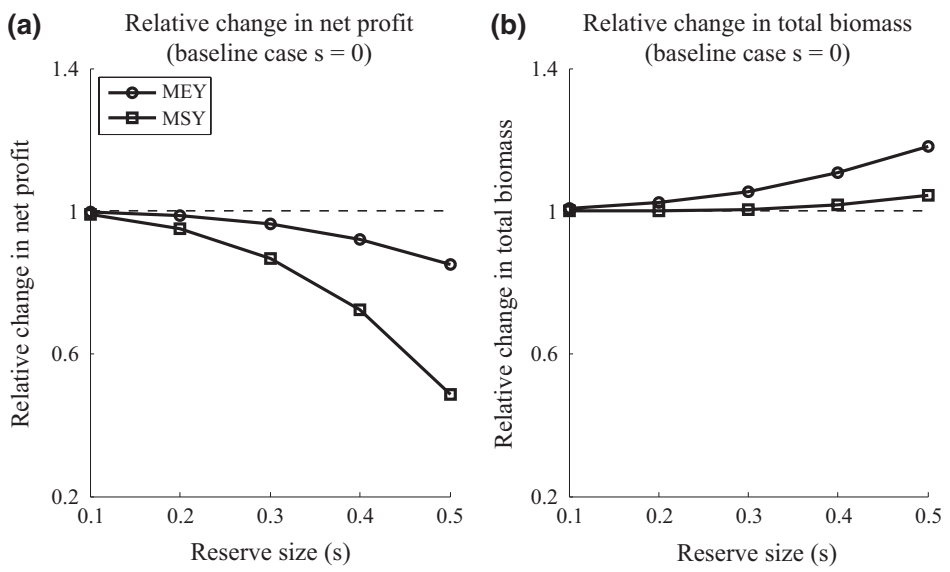

Figure 1 Relative effects of reserve size on the (a) net profit and (b) total biomass in a deterministic environment under a $\mathrm{B}_{\mathrm{MEY}}$ target and a $\mathrm{B}_{\mathrm{MSY}}$ target.

$$
\begin{aligned}
& \bar{\pi}(s) / \bar{\pi}(0) \quad \text { and } \quad \bar{x}(s) / \bar{x}(0) \\
& \text { where } s \in\{0.1,0.2,0.3,0.4,0.5\}
\end{aligned}
$$

Figure 1a shows that the relative net profit of fishing, evaluated at the steady state, decreases monotonically with the reserve size under both biomass targets. In a deterministic environment, designating a share of the carrying capacity as a reserve decreases the exploitable biomass and, regardless of the target, reduces the net profit of fishing. Nevertheless, for the range of the reserve size examined, the economic loss from implementing a no-take reserve in conjunction with the $\mathrm{B}_{\mathrm{MEY}}$ target is smaller than the loss associated with the $\mathrm{B}_{\mathrm{MSY}}$ target. In other words, the decrease in the exploitable biomass because of the increased size of the reserve is less when the off-reserve target is associated with $\mathrm{B}_{\mathrm{MEY}}$ than with $\mathrm{B}_{\mathrm{MSY}}$. This is because the greater is the density of the harvest population under the $\mathrm{B}_{\mathrm{MEY}}$ target, the smaller is the harvesting cost and the higher is the net profit of fishing for a given reserve size. We also observe that the total biomass increases monotonically as the size of the no-take reserve increases for both the $\mathrm{B}_{\mathrm{MSY}}$ and $\mathrm{B}_{\mathrm{MEY}}$ targets (Fig. 1b), but the gain in the total biomass is greater for any given reserve size examined when $\mathrm{B}_{\mathrm{MEY}}$ is adopted as the management target than when the $\mathrm{B}_{\mathrm{MSY}}$ target is adopted.

\section{Opportunity cost of increasing biomass in a deterministic environment}

The trade-off between the conservation benefit of the no-take reserve, as measured by total biomass, and the economic return of the fishery, as measured by net profit, from establishing a reserve in a deterministic environment is consistent with previous studies (e.g. Conrad 1999). Namely, as shown in Fig. 1, the larger the reserve the greater the trade-off. To assess the degree of this trade-off with a $\mathrm{B}_{\mathrm{MSY}}$ and with a $\mathrm{B}_{\mathrm{MEY}}$ target, we calculate the opportunity cost of increasing the reserve size. This cost is defined as the forgone fishery profit for each additional tonne of the total biomass secured because of the increased size of the reserve and is defined in (15) by:

$$
\text { Opportunity cost }=\frac{\bar{\pi}\left(s_{0}+\Delta s\right)-\bar{\pi}\left(s_{0}\right)}{\bar{x}\left(s_{0}+\Delta s\right)-\bar{x}\left(s_{0}\right)}
$$

where $s_{0}$ is the initial size of the no-take reserve with values set at $s_{0} \in\{0,0.1,0.2,0.3,0.4\}, \Delta s$ is the increment of the reserve size and $\Delta s=0.1$. Under these specifications, the opportunity cost represents the change in the net profit of fishing per unit change in the total biomass as a result of a $10 \%$ increase in reserve size.

Table 1 shows that, for all values of $s_{0}$ examined, the opportunity cost of securing additional biomass is always lower when the reserve size is increased in conjunction with the $\mathrm{B}_{\mathrm{MEY}}$ target than with the $\mathrm{B}_{\mathrm{MSY}}$ target. For instance, the opportunity cost of increasing total biomass is $\$ 110$ per tonne when this is achieved by increasing reserve size from $0 \%$ to $10 \%$ under the $\mathrm{B}_{\mathrm{MEY}}$ target, whereas the cost is $\$ 66390$ per tonne under the $\mathrm{B}_{\mathrm{MSY}}$ target. The table also shows that the greater the initial size of the no-take reserve, the smaller the difference in the opportunity cost between the two biomass targets. For instance, an 
Table 1 Opportunity cost of increasing the reserve size in a deterministic environment (\$000).

\begin{tabular}{lrrrrr}
\hline \multicolumn{5}{l}{ Change in reserve size } \\
\cline { 2 - 5 } & $0-10 \%$ & $10-20 \%$ & $20-30 \%$ & $30-40 \%$ & $40-50 \%$ \\
\hline MEY & -0.11 & -0.23 & -0.26 & -0.29 & -0.33 \\
MSY & -66.39 & -17.41 & -7.45 & -4.33 & -2.93 \\
\hline
\end{tabular}

The numbers represent the change in the net profit of fishing for each additional tonne of the total biomass secured because of increasing the reserve size by $10 \%$.

additional tonne of biomass secured by increasing reserve size from $40 \%$ to $50 \%$ of the carrying capacity under a $\mathrm{B}_{\mathrm{MSY}}$ target carries an opportunity cost about nine times higher than when combined with a $\mathrm{B}_{\mathrm{MEY}}$ target.

\section{Economic returns and total biomass in a stochastic environment}

We simulate 100000 Monte Carlo samples (indexed by $i=1,2, \cdots, M$ ) of the NPV of fishing and average total biomass over 100 years where the fishing value is discounted at $5 \%$ per year to compare the effects of the two biomass targets in a stochastic environment. The NPV of fishing and average total biomass is computed for three different sizes of the no-take reserve, $10 \%, 30 \%$ and $50 \%$ of the carrying capacity, and each outcome is then standardized relative to the no-reserve case $(s=0)$, that is:
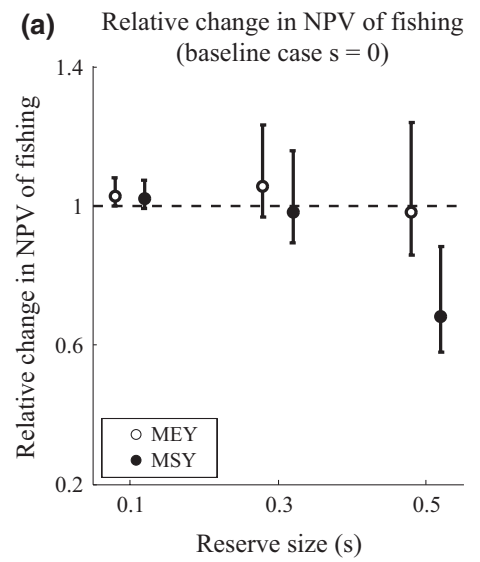

$$
N P V^{i}(s) / N P V^{i}(0) \text { and } \sum_{t=0}^{T} x_{t}^{i}(s) / \sum_{t=0}^{T} x_{t}^{i}(0)
$$

where $s \in(0.1,0.3,0.5\}, \quad M=100000$ and $T=99$.

Figure 2 illustrates the mean values of the relative change in the NPV of fishing (Fig. 2a) and the average total biomass (Fig. 2b) with error bars that represent a 95\% confidence interval. The figures show that, as in the deterministic case, in the presence of environmental uncertainties, the average total biomass increases with the increased reserve size (Fig. 2b). However, unlike the deterministic case, the NPV of fishing does not necessarily decrease with increases in the reserve size for either the $\mathrm{B}_{\mathrm{MEY}}$ or $\mathrm{B}_{\mathrm{MSY}}$ targets (Fig. 2a).

We note that the no-take reserve provides a buffer against environmental uncertainties, regardless of which target is selected, and thus, the economic rent of the fishery may increase with the size of the reserve (Grafton et al. 2006). For instance, reserving $10 \%$ of the carrying capacity, on average, increases the NPV of fishing and average total biomass by $2.6 \%$ and $2.2 \%$ when the management target is $\mathrm{B}_{\mathrm{MEY}}$. Similarly, when the $\mathrm{B}_{\mathrm{MSY}}$ is adopted as the management target, the NPV of fishing and average total biomass increase on average by $2.0 \%$ and $1.5 \%$.

We find that only in the case of reserving $50 \%$ of the carrying capacity in a $\mathrm{B}_{\mathrm{MSY}}$ target-managed fishery, there is clear evidence of a trade-off between the conservation benefits of reserve establishment and economic returns in the fishery (Fig. 2). While the total biomass increases on average by $11.0 \%$ relative

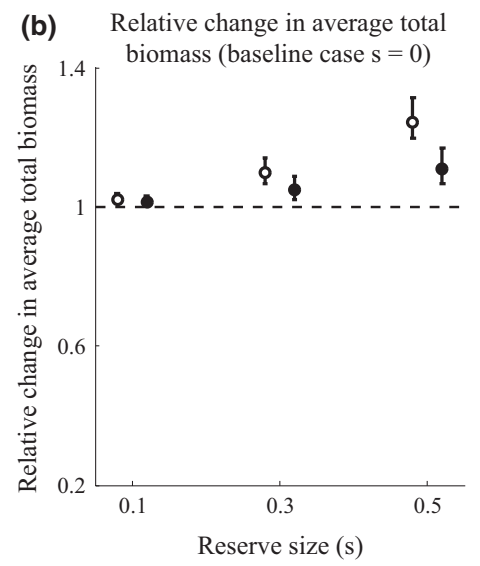

Figure 2 Relative effects of reserve size on the (a) NPV of fishing and (b) average total biomass in a stochastic environment under a $B_{\mathrm{MEY}}$ target and a $\mathrm{B}_{\mathrm{MSY}}$ target. Error bars represent a $95 \%$ confidence interval. 
to the no-reserve case when the reserve size is set at $50 \%$ of the carrying capacity, there is a more than 95\% chance that the NPV of fishing decreases in the $\mathrm{B}_{\mathrm{MSY}}$ managed fishery. The use of $\mathrm{B}_{\mathrm{MEY}}$ as the management target weakens this trade-off between the conservation and fishery benefits, even in the extreme case of a reserve that encompasses $50 \%$ of the carrying capacity. Under a $\mathrm{B}_{\mathrm{MEY}}$ target, while the total biomass increases on average by $24.4 \%$ relative to the no-reserve case, there is still a $32 \%$ chance that the NPV of the fishery will increase.

\section{Opportunity cost of increasing biomass in a stochastic environment}

For all reserve sizes examined in the stochastic environment, the relative gain in average total biomass is larger when the $\mathrm{B}_{\mathrm{MEY}}$ target is adopted than when the $\mathrm{B}_{\mathrm{MSY}}$ target is used (Fig. 2). In addition, the relative cost of reserve establishment in terms of a reduced mean NPV of fishing is less in the $\mathrm{B}_{\mathrm{MEY}}$ managed fishery. As is the deterministic case, we calculate the opportunity cost in terms of the foregone NPV of fishing for securing additional units of average total biomass as the reserve size increases in a stochastic environment. The mean opportunity cost is calculated as follows:

Mean opportunity

$$
\begin{aligned}
\operatorname{cost}= & \frac{1}{M} \sum_{i=1}^{M} \\
& {\left[\frac{N P V^{i}\left(s_{0}+\Delta s\right)-N P V^{i}\left(s_{0}\right)}{\frac{1}{T}\left(\sum_{t=0}^{T} x_{t}^{i}\left(s_{0}+\Delta s\right)-\sum_{t=0}^{T} x_{t}^{i}\left(s_{0}\right)\right)}\right] }
\end{aligned}
$$

where $M=100000, \quad T=100, \quad \Delta s=0.1 \quad$ and $s_{0} \in\{0,0.1,0.2,0.3,0.4\}$.

Table 2 shows that the mean opportunity cost of increasing average total biomass by expanding the reserve size by $10 \%$ is positive when the initial size of the no-take reserve is small. For instance, when the reserve size is extended from $0 \%$ to $10 \%$ of the carrying capacity in conjunction with the $\mathrm{B}_{\mathrm{MEY}}$ target, the NPV of the fishery on average increases by $\$ 5690$ per additional tonne of average total biomass. Similarly, when $\mathrm{B}_{\mathrm{MSY}}$ is used as the management target, the NPV of fishing on average increases by $\$ 4870$ per additional tonne of the total biomass. This double payoff of the no-take reserve is consistent with the results in
Table 2 Mean opportunity cost of increasing the reserve size in a stochastic environment (\$000).

\begin{tabular}{llrrrr}
\hline \multicolumn{5}{c}{ Change in reserve size } \\
\cline { 2 - 6 } & $0-10 \%$ & $10-20 \%$ & $20-30 \%$ & $30-40 \%$ & $40-50 \%$ \\
& & & & & \\
\hline MEY & 5.69 & 2.40 & -0.01 & -2.21 & -4.07 \\
MSY & 4.87 & -6.51 & -20.17 & -28.33 & -31.38 \\
& & & & & \\
\hline
\end{tabular}

The numbers represent the change in the mean NPV of fishing for each additional tonne of the average total biomass secured because of increasing the reserve size by $10 \%$.

Fig. 2. Namely, the relative change in the NPV of fishing and the average total biomass because of the $10 \%$ reserve are both greater than one regardless of which biomass target is selected.

Similar to the deterministic case, for all ranges of the change in the reserve size investigated, the opportunity cost of increased average total biomass is less when it is secured by increasing the proportion of the carrying capacity that is reserved under the $\mathrm{B}_{\mathrm{MEY}}$ target than under the $\mathrm{B}_{\mathrm{MSY}}$ target. We also observe that the opportunity cost of this additional biomass becomes larger as the initial reserve size increases for both biomass targets.

\section{Environmental uncertainty and optimal reserve size}

\section{Effects of reserve size and environmental uncertainty}

Figure 3 illustrates the mean difference in the NPV of fishing (Fig. 3a) and average total biomass (Fig. 3b) between the $\mathrm{B}_{\mathrm{MEY}}$ and $\mathrm{B}_{\mathrm{MSY}}$ targets for a range of combinations of reserve size and the rate at which fishing activity imposes a negative shock on the harvest population. The mean differences are, respectively, defined as:

$$
\begin{aligned}
& \frac{1}{M} \sum_{i=1}^{M}\left[N P V_{M E Y}^{i}-N P V_{M S Y}^{i}\right] \text { and } \\
& \frac{1}{M} \sum_{i=1}^{M}\left[\frac{1}{T} \sum_{t=0}^{T}\left(x_{t, M E Y}^{i}-x_{t, M S Y}^{i}\right)\right] .
\end{aligned}
$$

For all combinations of the reserve size $(s)$ and arrival rate of negative shocks $(\alpha)$ investigated, the 
(a)

Difference in NPV of fishing

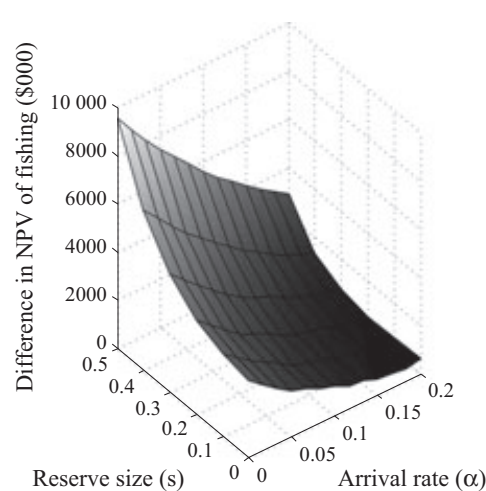

(b) Difference in average total biomass

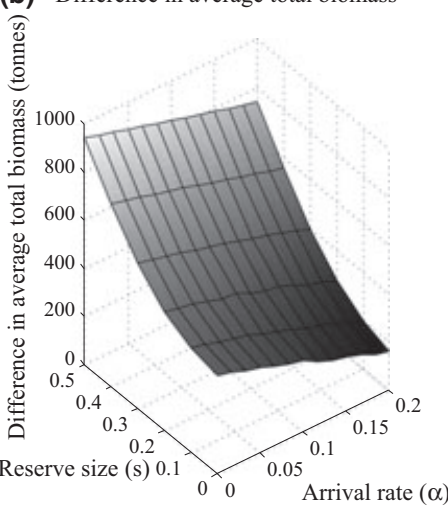

Figure 3 Mean difference in the (a) NPV of fishing and (b) average total biomass between the $B_{M E Y}$ and $B_{M S Y}$ targets for different combinations of reserve size $(s)$ and the arrival rate of negative shocks $(\alpha)$.

NPV of fishing and average total biomass are both greater when the fishery is operated in conjunction with the $\mathrm{B}_{\mathrm{MEY}}$ target level than with the $\mathrm{B}_{\mathrm{MSY}}$ target. For instance, given a reserve size of $30 \%$ and an arrival rate of $3.3 \%$, the NPV of the fishery and the average total biomass are $\$ 3.9$ million and 500 tonnes greater when the management target is associated with $\mathrm{B}_{\mathrm{MEY}}$ than with $\mathrm{B}_{\mathrm{MSY}}$.

We also find that for all arrival rates considered that the larger the proportion of the carrying capacity placed in the no-take reserve, the greater the advantage of the $\mathrm{B}_{\mathrm{MEY}}$ target over the $\mathrm{B}_{\mathrm{MSY}}$ target in terms of the average total biomass. Similarly, the difference between the NPV of fishing under the $\mathrm{B}_{\mathrm{MEY}}$ target and that under the $\mathrm{B}_{\mathrm{MSY}}$ target increases monotonically with the reserve size for all arrival rates in the range. These results suggest that for a fishery with a given arrival rate of negative shocks and share of the carrying capacity designated as a no-take reserve, implementing a $\mathrm{B}_{\mathrm{MEY}}$ target will have an advantage over a $\mathrm{B}_{\mathrm{MSY}}$ target in terms of both the conservation and economic value of the fishery. Moreover, this result does not qualitatively change if we allow for the occurrence of identical negative shocks on both the harvest and reserve populations.

\section{Optimal reserve size}

The optimal design of a no-take reserve depends on biological and economic parameters in the fishery (Hilborn et al. 2004; Grafton et al. 2006; Sanchirico et al. 2006; White et al. 2008). To evaluate the effects of parameter changes on the results, we assess how optimal reserve size is affected by the choice of biomass target in the fishery for a range of key biological and economic parameters. We re-simulate the model for the two biomass targets, but use different values of the transfer coefficient $(m)$, intrinsic growth rate $(r)$, harvesting cost parameter (c) and strength of the stock effect $(b)$. In these results, we identify the optimal reserve size $\left(s^{*}\right)$ as the proportion of the carrying capacity that is designated as a no-take reserve that maximizes the mean NPV of fishing, that is:

$$
s * \in \underset{s \in[0,1]}{\arg \max }\left\{\frac{1}{M} \sum_{i=1}^{M} N P V^{\mathrm{i}}(s)\right\} .
$$

Figure 4 shows that the optimal reserve size for the $\mathrm{B}_{\mathrm{MEY}}$ target is greater than or equal to that for the $\mathrm{B}_{\mathrm{MSY}}$ target for all parameters and their regions examined. The qualitative effect of an increase in a given parameter value, holding everything else constant, is also summarized in Table 3.

An increase in the value of the transfer coefficient $(m)$, which captures the strength of the spillover between the harvest and reserve populations, increases optimal reserve size under both biomass targets (Table 3). The difference in the optimal reserve size, however, between the $\mathrm{B}_{\mathrm{MEY}}$ and $\mathrm{B}_{\mathrm{MSY}}$ targets increases with the increase of the transfer coefficient, ceteris paribus (Fig. 4a). For instance, given $m=0.2$, the optimal reserve size is $16 \%$ greater when the no-take reserve is established under the $\mathrm{B}_{\mathrm{MEY}}$ target than when $\mathrm{B}_{\mathrm{MSY}}$ is used as the management target. By contrast, the optimal reserve size is $S *=0$ for both biomass targets when 
(a) Transfer coefficient

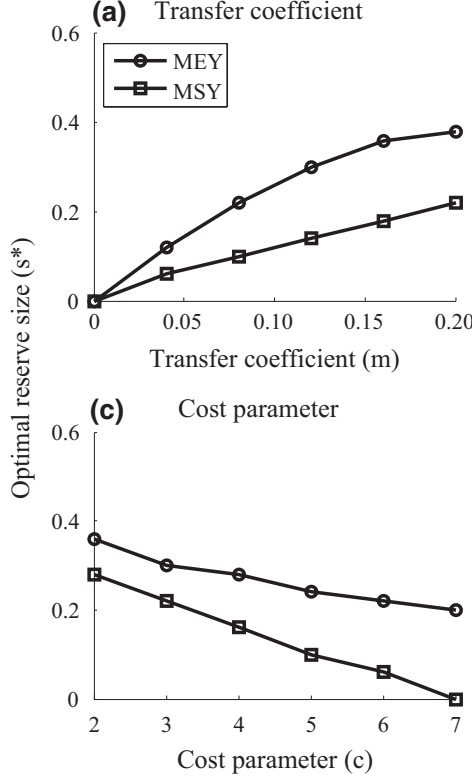

(b) Intrinsic growth rate
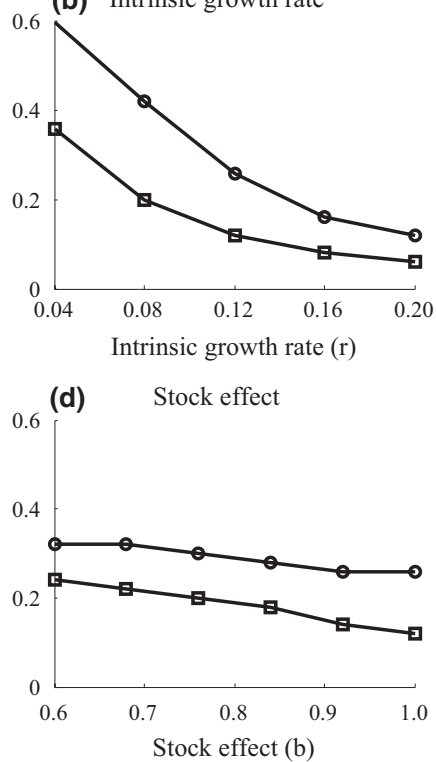

Figure 4 Optimal reserve size for different values of the biological and economics parameters under a $\mathrm{B}_{\mathrm{MEY}}$ target and a $\mathrm{B}_{\mathrm{MSY}}$ target.

Table 3 Effects of marginal increase in parameter values on the optimal reserve size $\left(s^{*}\right)$.

\begin{tabular}{llll}
\hline & Intrinsic & & \\
$\begin{array}{l}\text { Transfer } \\
\text { coefficient }(m)\end{array}$ & $\begin{array}{l}\text { growth } \\
\text { rate }(r)\end{array}$ & $\begin{array}{l}\text { Cost } \\
\text { parameter }(c)\end{array}$ & $\begin{array}{l}\text { Stock } \\
\text { effect }(b)\end{array}$ \\
\hline+ & & & - \\
\hline
\end{tabular}

'+' indicates that a marginal increase in the given parameter value, holding everything else constant, will increase the optimal reserve size, while '-' indicates it will decrease the optimal reserve size.

there is no spillover between harvest and reserve populations.

Increases in the value of the intrinsic growth rate $(r)$, harvesting cost parameter $(c)$ and strength of the stock effect $(b)$ all result in a decrease in the optimal reserve size under both biomass targets (Table 3). As is the case with the transfer coefficient, the difference between the optimal reserve size under the alternative targets increases as the harvesting cost parameter increases, with the optimal reserve size falling to $0 \%$ under the $B_{M S Y}$ target when $c=7$ (Fig. 4c). The difference between the optimal reserve size for the two biomass targets is also sensitive to the size of the intrinsic growth rate (Fig. 4b). The reserve size that maximizes the
NPV of fishing in the $\mathrm{B}_{\mathrm{MEY}}$ managed fishery is $24 \%$ greater than for the $\mathrm{B}_{\mathrm{MSY}}$ managed fishery for $r=0.04$, but only $6 \%$ greater for the case of a faster growing species $(r=0.2)$. The effect on the optimal reserve size and its difference between the two biomass targets are less marked for changes in the strength of the stock effect (Fig. 4d). With a stock effect equal to $b=0.6$, the optimal $\mathrm{B}_{\mathrm{MSY}}$ reserve size is $8 \%$ smaller than the size of the $\mathrm{B}_{\mathrm{MEY}}$ reserve. While the difference between the two optimum increases as the strength of the stock effect increases, the optimal $\mathrm{B}_{\mathrm{MSY}}$ reserve size is $14 \%$ smaller than the size of the optimum $\mathrm{B}_{\mathrm{MEY}}$ reserve for the benchmark case $(b=1)$.

\section{Conclusions}

Following the seminal paper by Gordon (1954), the merits of alternative management targets in marine capture fisheries have been the focus of much debate. Indeed, several recent studies have highlighted differences in the equilibrium level of biomass, fishing effort and fishery profits between the $\mathrm{B}_{\mathrm{MSY}}$ and $\mathrm{B}_{\mathrm{MEY}}$ targets (Grafton et al. 2007, 2010, 2012; Christensen 2010; Clark et al. 2010; Sumaila and Hannesson 2010). Separate to these comparisons, and over the past decade or so, no-take marine reserves have increasingly become a key management strategy to assist in stock 
recovery in many fisheries. While previous studies have found that whether the benefits of no-take reserves are realized depends critically on fisheries management outside the reserves (Sanchirico and Wilen 2002; Smith and Wilen 2003; Sumaila and Armstrong 2006; Ruijs and Janmaat 2007; Little et al. 2011), until now there has been no study that models and quantifies the effects of the biomass management target on the conservation and economic benefits of a reserve.

To evaluate the effects of biomass targets on the payoffs of establishing a no-take reserve, a parameterized model based on the red throat emperor fishery on the Great Barrier Reef in Australia is developed. Model results show that, for a wide range of scenarios, the conservation and economic objectives are greater when the no-take reserve is established in conjunction with a $\mathrm{B}_{\mathrm{MEY}}$ target than when $\mathrm{B}_{\mathrm{MSY}}$ is the management target. The findings show that the opportunity cost of securing additional biomass, in both deterministic and stochastic environments, is lower when the reserve size is increased under the $\mathrm{B}_{\mathrm{MEY}}$ target. This is an important result because marine reserves have been established as a key management strategy to restore depleted fish stocks, and our findings suggest that this objective can be achieved with lower economic costs when $\mathrm{B}_{\mathrm{MEY}}$ is adopted as the management target rather than with the default management target applied in many fisheries of $\mathrm{B}_{\mathrm{MSY}}$.

A key contribution of our study is to show that the advantage of the $\mathrm{B}_{\mathrm{MEY}}$ target over the $\mathrm{B}_{\mathrm{MSY}}$ target in terms of the level of biomass and economic returns of fishing is greater than predicted by previous studies (Gordon 1954; Smith 1969) if the comparison is made with the establishment of a no-take reserve. In essence, the economic payoff to establishing a no-take reserve, which arises as a result of the spillover of exploitable biomass from the reserve to the harvest population, is not fully captured when the off-reserve fishery is managed using the $\mathrm{B}_{\mathrm{MSY}}$ target. As a consequence, the relative gain in the NPV of fishing is greater when the reserve is implemented in conjunction with the $\mathrm{B}_{\mathrm{MEY}}$ target than when the target is associated with $\mathrm{B}_{\mathrm{MSY}}$.

The model results show that the optimal reserve size under the $\mathrm{B}_{\mathrm{MEY}}$ target is greater than that under the $\mathrm{B}_{\mathrm{MSY}}$ target and that this is the case for a wide range of assumptions about the rate at which negative biomass shocks will be experienced in the harvested population. The two management targets, however, are equivalent in terms of the optimal reserve size, when there are no spillovers from the no-take reserve to the exploited part of the fishery. In this case, no reserve is the optimal strategy under both the $\mathrm{B}_{\mathrm{MEY}}$ and $\mathrm{B}_{\mathrm{MSY}}$ targets if the management objective is to maximize the net present value of profits from fishing.

Two important caveats need to be applied when applying our results to other fisheries. First, the bioeconomic model constructed in this paper is a single-species model parameterized for the red throat emperor fishery in Queensland, Australia. While this fishery is managed as a single stock on the Australian Great Barrier Reef, most coral reef fisheries globally are managed as part of multispecies fisheries. Second, we use the total biomass of the exploited species and the economic return of fishing as measures of the conservation and economic values of the fishery. In general, however, the effects of no-take marine reserves extend beyond changes in the biomass and harvest value of the target fish population and would include species interactions, habitat structures and the non-consumptive value of marine resources (Bhat 2003; Shears and Babcock 2003; Micheli et al. 2004). A more complete comparison of the effects of the two biomass targets, therefore, would extend to address questions related to multispecies coral reef fisheries and to incorporate key ecosystem values of the fishery.

Overall, our results demonstrate that adopting a bioeconomic management target rather than a strict biological target can provide greater conservation and economic benefits if the fishery is also managed with a no-take reserve. Our findings offer the possibility of 'win-win' outcomes if reserves are combined with a $\mathrm{B}_{\mathrm{MEY}}$ target. Given that no-take reserves are increasingly being used as a key fisheries management tool, in combination with other management strategies, understanding the way in which no-take reserves impact both on and off reserve values, and the dependency of conservation and economic effects on off-reserve fisheries management makes our conclusions pertinent and ongoing work in the area important.

\section{Acknowledgements}

We are grateful for the comments and suggestions from two anonymous reviewers. The work was funded by the University of Tasmania and the Commonwealth Environmental Research Facility. 


\section{References}

Abesamis, R.A. and Russ, G.W. (2005) Density-dependent spillover from a marine reserve: long-term evidence. Ecological Applications 15, 1798-1812.

Allison, G.W., Lubchenco, J. and Carr, M.H. (1998) Marine reserves are necessary but not sufficient for marine conservation. Ecological Applications 8, S79-S92.

Beddington, J.R., Agnew, D.J. and Clark, C.W. (2007) Current problems in the management of marine fisheries. Science 22, 1713-1716.

Bhat, M.G. (2003) Application of no-market valuation to the Florida Keys marine reserve management. Journal of Environmental Management 67, 315-325.

Caddy, J.F. and Agnew, D.J. (2004) An overview of recent global experience with recovery plans for depleted marine resources and suggested guidelines for recovery planning. Reviews in Fish Biology and Fisheries 14, 43-112.

Christensen, V. (2010) MEY = MSY. Fish and Fisheries 11, 105-110.

Clark, C.W. (1973) Profit maximization and the extinction of animal species. Journal of Political Economy 81, 950-961.

Clark, C.W. (1990) Mathematical Bioeconomics: The Optimal Management of Renewable Resources, 2nd edn. John Wiley \& Sons, New York.

Clark, C.W. and Munro, G.R. (1975) The economics of fishing and modern capital theory: a simplified approach. Journal of Environmental Economics and Management 2, 92-106.

Clark, C.W., Munro, G.R. and Sumaila, U.R. (2010) Limits to the privatization of fishery resources. Land Economics 86, 209-218.

Conrad, J.M. (1999) The bioeconomics of marine sanctuaries. Journal of Bioeconomics 1, 205-217.

Costello, C. and Polasky, S. (2008) Optimal harvesting of stochastic spatial resources. Journal of Environmental Economics and Management 56, 1-18.

Dichmont, C.M., Pascoe, S., Kompas, T., Punt, A.E. and Deng, R. (2010) On implementing maximum economic yield in commercial fisheries. Proceedings of the National Academy of Sciences 107, 16-21.

Froese, R., Branch, T.A., Proel $\beta$, A., Quaas, M., Sainsbury, K. and Zimmermann, C. (2011) Generic harvest control rules for European fisheries. Fish and Fisheries 12, 340-351.

Goñi, R., Hilborn, R., Díaz, D., Sandra, M. and Adlerstein, S. (2010) Net contribution of spillover from a marine reserve to fishery catches. Marine Ecology Progress Series 400, 233-243.

Gordon, H.S. (1954) The economic theory of a commonproperty resource: the fishery. Journal of Political Economy 62, 124-142.

Grafton, R.Q., Kompas, T. and Lindenmayer, D. (2005) Marine reserves with ecological uncertainty. Bulletin of Mathematical Biology 67, 957-971.
Grafton, R.Q., Kompas, T. and Ha, P.V. (2006) The economic payoffs from marine reserves: resource rents in a stochastic environment. Economic Record 82, 469-480.

Grafton, R.Q., Kompas, T. and Hilborn, R. (2007) Economics of overexploitation revisited. Science 318, 1601

Grafton, R.Q., Kompas, T. and Ha, P.V. (2009) Cod today and none tomorrow: the economic value of a marine reserve. Land Economics 85, 454-469.

Grafton, R.Q., Kompas, T., Chu, L. and Che, N. (2010) Maximum economic yield. Australian Journal of Agricultural and Resource Economics 54, 273-280.

Grafton, R.Q., Kompas, T., Che, T.N., Chu, L. and Hilborn, R. (2012) $\mathrm{B}_{\mathrm{MEY}}$ as a fisheries management target. Fish and Fisheries 13, 303-312.

Halpern, B.S. (2003) The impact of marine reserves: do reserves work and does reserve size matter? Ecological Applications 13, S117-S137.

Halpern, B.S., Regan, H.M., Possingham, H.P. and McCarthy, M.A. (2006) Accounting for uncertainty in marine reserve design. Ecology Letters 9, 2-11.

Hannesson, R. (1998) Marine reserves: what would they accomplish? Marine Resource Economics 13, 159-170.

Hilborn, R. (2007) Defining success in fisheries and conflicts in objectives. Marine Policy 31, 153-158.

Hilborn, R., Stokes, K., Maguire, J.J. et al. (2004) When can marine reserves improve fisheries management? Ocean \& Coastal Management 47, 197-205.

Jennings, S. (2001) Patterns and prediction of population recovery in marine reserves. Reviews in Fish Biology and Fisheries 10, 209-231.

Kompas, T., Dichmont, C.M., Punt, A.E. et al. (2010) Maximizing profits and conserving stocks in the Australian Northern Prawn Fishery. Australian Journal of Agricultural and Resource Economics 54, 281-299.

Kramer, D.L. and Chapman, M.R. (1999) Implications of fish home range size and relocation for marine reserve function. Environmental Biology of Fishes 55, 65-79.

Larkin, P. A. (1977) An epitaph for the concept of maximum sustainable yield. Transactions of American Fisheries Society 1, 1-11.

Lauck, T., Clark, C.W., Mangel, M. and Munro, G.R. (1998) Implementing the precautionary principle in fisheries management through marine reserves. Ecological Applications 8, S72-S78.

Leigh, G.M., Williams, A., Begg, G.A., Gribble, N.A. and Whybird, O.J. (2006) Stock Assessment of the Queensland East Coast Red Throat Emperor (Lethrinus miniatus) Fishery. The State of Queensland, Department of Primary Industries and Fisheries,, Brisbane.

Lester, S.E., Halpern, B.S., Grorud-Colvert, K. et al. (2009) Biological effects within no-take marine reserves: a global synthesis. Marine Ecology Progress Series 384, 33-46.

Little, L.R., Begg, G.A., Goldman, B. et al. (2008) Modelling Individual Transferable Quotas as a Management Tool in the Queensland Coral Reef Fin Fishery. Fisheries 
Research and Development Corporation, Townsville, Qld.

Little, L.R., Punt, A.E., Mapstone, B.D., Begg, G.A., Goldman, B. and Williams, A. (2009) An agent-based model for simulating trading of multiple-species fisheries quota. Ecological Modelling 220, 3404-3412.

Little, L.R., Grafton, R.Q., Kompas, T., Smith, A.D.M. and Punt, A.E. (2011) Complementarity of no-take marine reserves and individual transferable catch quotas for managing the line fishery of the Great Barrier Reef. Conservation Biology 25, 333-340.

Mace, P.M. (2001) A new role for MSY in single-species and ecosystem approaches to fisheries stock assessment and management. Fish and Fisheries 2, 2-32.

Mangel, M. (2000) Irreducible uncertainties, sustainable fisheries and marine reserves. Evolutionary Ecology Research 2, 547-557.

McClanahan, T.R. (2010) Effects of fisheries closures and gear restrictions on fishing income in a Kenyan coral reef. Conservation Biology 24, 1519-1528.

Micheli, F., Halpern, B.S., Botsford, L.W. and Warner, R. R. (2004) Trajectories and correlates of community change in no-take marine reserves. Ecological Applications 14, 1709-1723.

Pelc, R.A., Warner, R.R., Gaines, S.D. and Paris, C.B. (2010) Detecting larval export from marine reserves. Proceedings of the National Academy of Sciences 107, 18266-18271.

Pezzey, J.C.V., Roberts, C.M. and Urdal, B.T. (2000) A simple bioeconomic model of a marine reserve. Ecological Economics 33, 77-91.

Punt, A.E. and Smith, A.D.M. (2001) The gospel of maximum sustainable yield in fisheries management: birth, crucifixion and reincarnation. In: Conservation of Exploited Species (eds J.D. Renynolds, G.M. Mace, K.H. Redford and J.G. Robinson). Cambridge University Press, Cambridge, pp. 41-66.

Roberts, C.M., Bohnsach, J.A., Gell, F.R., Hawkins, J.P. and Goodridge, R. (2001) Effects of marine reserves on adjacent fisheries. Science 294, 1920-1923.

Roberts, C.M., Hawkins, J.P. and Gell, F.R. (2005) The role of marine reserves in achieving sustainable fisheries. Philosophical Transactions of the Royal Society $B$ 360, 123-132.
Ruijs, A. and Janmaat, J.A. (2007) Chasing the spillovers: locating protected areas in a trans-boundary fishery. Land Economics 83, 6-22.

Sanchirico, J.N. and Wilen, J.E. (2001) A bioeconomic model of marine reserve creation. Journal of Environmental Economics and Management 42, 257-276.

Sanchirico, J.N. and Wilen, J.E. (2002) The impact of marine reserves on limited-entry fisheries. Natural Resource Modeling 15, 291-310.

Sanchirico, J.N., Malvadkar, U., Hastings, A. and Wilen, J.E. (2006) When are no-take zones an economically optimal fishery management strategy? Ecological Applications 16, 1643-1659.

Shears, N.T. and Babcock, R.C. (2003) Continuing Cascade effects after 25 years of no-take marine reserve protection. Marine Ecology and Progress Series 246, 1-16.

Smith, V.L. (1969) On models of commercial fishing. Journal of Political Economy 77, 181-198.

Smith, M.D. and Wilen, J.E. (2003) Economic impacts of marine reserves: the importance of spatial behavior. Journal of Environmental Economics and Management 46, 183-206.

Stobart, B., Warwick, R., González, C. et al. (2009) Longterm and spillover effects of a marine protected area on an exploited fish community. Marine Ecology Progress Series 384, 47-60.

Sumaila, U.R. (1998) Protected marine reserves as fisheries management tools: a bioeconomic analysis. Fisheries Research 37, 287-296.

Sumaila, U.R. and Armstrong, C.W. (2006) Distributional and efficiency effects of marine protected areas: a study of the Northeast Atlantic cod fishery. Land Economics 82, 321-332.

Sumaila, U.R. and Hannesson, R. (2010) Maximum economic yield in crisis? Fish and Fisheries 11, 461-465.

Vandeperre, F., Higgins, R.M., Sánchez-Meca, J. et al. (2011) Effects of no-take area size and age of marine protected areas on fisheries yields: a meta-analytical approach. Fish and Fisheries 12, 412-426.

White, C., Kendall, B.E., Gaines, S., Siegal, D.A. and Costello, C. (2008) Marine reserve effects on fishery profit. Ecology Letters 11, 370-379.

Worm, B., Hilborn, R., Baum, J.K. et al. (2009) Rebuilding global fisheries. Science 325, 578-585. 